\title{
HRM practices sustaining PSM: when values congruency matters
}

\section{David Giauque*}

University of Lausanne, IEPI, Géopolis,

1015 Lausanne, Switzerland

Email: david.giauque@unil.ch

*Corresponding author

\section{Simon Anderfuhren-Biget and Frédéric Varone}

\author{
University of Geneva, \\ 40, bvd Pont-d'Arve, \\ 1211 Genève, Switzerland \\ Email: Simon.Anderfuhren-Biget@unige.ch \\ Email: Frederic.Varone@unige.ch
}

\begin{abstract}
This study aims at identifying the organisational antecedents of public service motivation (PSM). It focuses on human resources management (HRM) practices as one category of organisational factors that impact on PSM. Concretely, this research questions how intrinsic and extrinsic HRM practices are related to PSM and whether these relationships are direct or mediated by person-organisation (P-O) fit. The empirical findings are based on a survey of 6,885 civil servants working in Switzerland. Regression analyses highlight that intrinsic HRM practices are positively related to PSM, whereas extrinsic ones are negatively related to PSM. Furthermore, mediation tests shows that only the intrinsic HRM practices are mediated by PO fit. Thus, civil servants who value intrinsic work incentives maintain a high PSM level when they perceive congruence between their individual expectations and the values of their organisation.
\end{abstract}

Keywords: public service motivation; PSM; human resources management; HRM; intrinsic incentives; extrinsic incentives; person-organisation fit.

Reference to this paper should be made as follows: Giauque, D., Anderfuhren-Biget, S. and Varone, F. (2015) 'HRM practices sustaining PSM: when values congruency matters', Int. J. Public Sector Performance Management, Vol. 2, No. 3, pp.202-220.

Biographical notes: David Giauque is a Professor at the University of Lausanne, member of the Institute of Political and International Studies. His research mainly concerns sociology of organisations and public administrations, public management, motivation and values, reforms, and their consequences in the public sector.

Simon Anderfuhren-Biget obtained his $\mathrm{PhD}$ in Political Science and is currently a Lecturer at the University of Geneva, Switzerland. His research interests include human resource management, organisational behaviour, and 
value-laden work motivation in the non-profit sector, public administrations, and international organisations.

Frédéric Varone is a Professor of Political Science at the University of Geneva, Switzerland. His research focuses on comparative policy analysis, program evaluation, and public sector reforms.

\section{Introduction ${ }^{1}$}

Public service motivation (PSM) is a concept widely studied by academics throughout the world. A number of scientific articles have been dedicated to the definition of the PSM concept (Perry, 2000; Vandenabeele, 2007), its empirical measurement (Coursey and Pandey, 2007; Kim, 2009), the identification of PSM outcomes or correlates (Bright, 2008; Moynihan and Pandey, 2007b), and the assessment of PSM antecedents (Camilleri, 2007). However, it is worth noting that organisational antecedents have been largely ignored by PSM scholars. To the best of our knowledge, very few scientific articles regarding this category of precursors have been published thus far (Giauque et al., 2013a; Gould-Williams et al., 2013). This lack of information concerning the potential effects of organisational dimensions on the emergence, development and maintenance of PSM has been precisely pointed out in recent publications in the field (Bright, 2008; Paarlberg et al., 2008). This study aims to help fill this information gap by investigating the conditions under which different human resources management (HRM) practices can be considered as organisational antecedents of PSM in public administrations.

Previous studies have demonstrated that HRM practices clearly contribute to shaping employees' perceptions regarding, for instance, workplace trust and organisational climate (Gould-Williams, 2003, 2007). This article follows a similar track but goes further to assess the extent to which HRM practices might also shape the level of PSM among public employees. In this respect, HRM strategies might be considered as organisational practices that could have profound impact on individuals' perceptions towards their job as well as their organisation. Some HRM practices might strengthen the fulfilment of personal aspirations under the organisational conditions they have to deal with, whereas others may weaken them. For instance, previous research has recurrently emphasised the risk of a 'crowding-out' effect when introducing extrinsic incentives through HRM practices such as 'pay for performance' to employees who especially value intrinsic rewards (Moynihan, 2010; Weibel et al., 2010). Other studies have also demonstrated that public employees are more sensitive to intrinsic work motivators than to extrinsic ones (Bright, 2009; Langbein, 2010). All these empirical results suggest that HRM practices must be considered in the explanation of PSM. Therefore, our first research question is as follows: To what extent do HRM practices influence the PSM level of public employees? The first research step will consist of testing this direct relationship between different types of organisational HRM practices and individual PSM levels.

The direct link between HRM practices and PSM level is, however, debatable. Given the fact that HRM practices might also influence how employees perceive the congruence between their own motives and needs and the values promoted by their organisation, it is also probable that person-organisation fit ( $\mathrm{P}-\mathrm{O}$ fit) might mediate the relationship between HRM practices and PSM. As Steijn (2008, p.14) recalls, 
"in a classic work, Vroom (1964) pointed out that there should be a fit between a person's characteristics and attitudes on the one hand and the workplace on the other. Lack of fit between these aspects can have negative effects. This point can be seen in the literature when the need is stressed for congruence between workers' motives and the incentives given by the organisation."

In other words, HRM practices may be considered as organisational incentives which greatly influence individuals' perceptions of fit between their own characteristics (in terms of values, goals or skills) and organisational ones. For the purpose of this article, we rely on the P-O fit approach, which captures one particular dimension of the more general concept of person-environment fit (Giauque et al., 2013b). We postulate that while some HRM practices might increase congruence between individuals' and their organisation's values (i.e., higher P-O fit), others can also be detrimental to P-O fit perception. In our study, we address this point by investigating the mediating effect of P-O fit on the relationship between HRM practices and PSM. Therefore, our second research question is: To what extent does the P-O fit of public employees mediate the influence of HRM practices on their PSM level?

This article provides new empirical evidence concerning the impact of organisational working conditions and HRM practices not only on PSM but also on P-O fit. In one word, it shows that civil servants who value intrinsic work incentives maintain a high PSM level when they perceive a fit between their individual expectations and the values of their organisation.

The remainder of the article proceeds as follows. First, we present the theoretical framework and research hypotheses of the relationships between organisational HRM practices, perceived P-O fit and individual PSM level. Data and methods are developed in the next section, followed by the exposé of our main empirical findings and a brief discussion of their limitations. Finally, the concluding section is devoted to the theoretical discussion and to the practical implications of this study.

\section{Theoretical framework}

The theoretical framework of this study hypothesises both a direct link between HRM practices and reported PSM level, and an indirect relationship that is mediated by the perceived P-O fit, as depicted in Figure 1. To briefly present this approach, we successively discuss the PSM concept as a dependent variable, the HRM practices as independent variables, and the $\mathrm{P}-\mathrm{O}$ fit as a mediating variable.

Figure 1 Theoretical framework

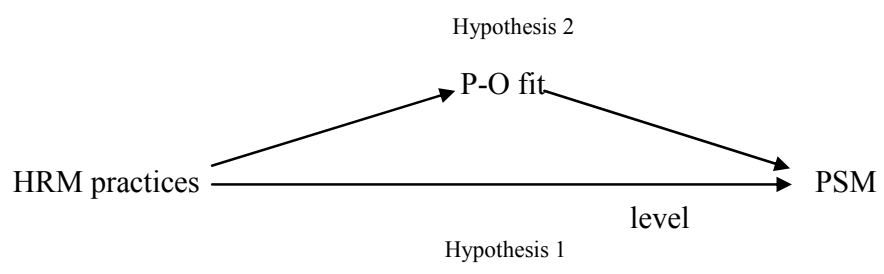




\subsection{Public service motivation}

In the 1990s, academic discussions of the PSM concept were primarily dedicated to its definition. The first attempt was based on a key assumption: values must be considered as a potential force enabling the personnel of public administrations to behave in a manner that may be of great benefit to their organisations. This statement was conceived to counter rational choice theories stressing that human behaviour could be exclusively explained by individual psychological mechanisms of self-interest. Hence, the PSM perspective "calls for a recommitment of Americans to values associated with government service, among them personal sacrifice and duty to the public interest, raise practical questions about the power of these values to stimulate and direct human behaviour" [Perry and Wise, (1990), p.367].

Thus, PSM was defined as motives associated primarily or exclusively with public administration and public service delivery. Based on such theoretical assumptions, the PSM concept was described as a multidimensional construct. Subsequently, the definition was re-specified and translated into a measurement scale based on four operational dimensions: attraction to policy making based on rational motives, commitment to the public interest emerging from norm-based motives, compassion linked to affective motives, and self-sacrifice associated with the willingness to substitute service to others for tangible personal rewards (Perry, 1996). Of course, the measurement of the PSM construct continues to be a disputed issue within the scientific community (Giauque et al., 2011; Kim et al., 2013).

A variety of empirical studies on PSM have explored its antecedents, correlates and outcomes in different countries and policy domains. Besides organisational antecedents, individual characteristics have been thoroughly analysed. Age, gender, and educational level are individual antecedents of PSM (Bright, 2005; Perry, 1997). Senior employees report a higher degree of PSM than their younger counterparts, men show a higher degree of PSM than women, with the exception of the compassion dimension for which they score higher, and public agents with a higher educational level also report a higher degree of PSM.

Additional predictors of PSM have also been identified at the organisational level. For instance, red tape (i.e., administrative constraints) seems to be negatively related to PSM (Scott and Pandey, 2005). In a similar vein, employees who experience employee-friendly organisational reforms designed to cut red tape and to empower employees display higher levels of PSM (Moynihan and Pandey, 2007a). In other words, administrative constraints may be reasonably considered as a hindrance in the PSM dynamics (Brewer and Walker, 2010). Furthermore, the relationship between job tenure and PSM has been found to be negative. Employees with long professional tenure in their organisation report a lower level of PSM than individuals who have belonged to their organisation for shorter periods of time.

It is rather surprising that only a few other organisational variables have been taken into account with respect to PSM. For instance, Moynihan and Pandey (2007b) have shown no significant relationship between organisational culture and PSM. Others have demonstrated that civil servants with different PSM orientations are not evenly distributed amongst policy domains and along stages of the policy cycle. They suggest that PSM is contingent on both organisational attributes (e.g., types of jobs depending on policy issues at stake and policy tasks performed) according to an individual's willingness to work in organisational contexts characterised by similar values 
(Anderfuhren-Biget et al., 2013). Finally, the results of empirical studies relating HRM practices to PSM indicate that civil servants with high PSM levels tend to favour those that promote intrinsic rewards (Giauque et al., 2013a). However, these empirical studies did not systematically control whether or not the positive relation between PSM and intrinsic rewards is influenced by how much civil servants personal values align those of the organisation they work for. Consequently, the aim of this study is to specifically check for these congruency effects and to empirically assess the impact of HRM practices on PSM level by taking into account the P-O fit as a mediating variable. The following sub-section presents why HRM practices are expected to constitute organisational antecedents of the individual PSM level and the second sub-section recalls PSM studies that take into account the value-congruency perspective.

\subsection{Human resources management}

One of the most common classifications of HRM practices in research on motivation relates to the internal versus external factors that sustain motivation at work. The intrinsic-extrinsic dichotomy was developed to analyse the reasons that employees deploy their energy in their professional tasks (Deci and Ryan, 1985). Broadly speaking, intrinsically motivated individuals are those who do their job for its own sake because they like and identify with the type and specific characteristics of the tasks performed. By contrast, the extrinsically motivated ones work for utilitarian reasons such as earning money or securing their professional position (Ryan and Deci, 2002). Without discussing all its facets, this classical approach has the obvious advantage of helping to classify HRM practices along those lines. It is also relevant with regards to the specificities of public agents' aspirations.

On this point, comparative studies have consistently shown that public and private employees are not alike specifically regarding the type of reward (monetary or non-monetary) preferred. Generally speaking, public employees do possess a greater desire for intrinsic, non-monetary opportunities than their private counterparts (Rainey and Bozeman, 2000). And this is even truer for civil servants with a high PSM level, as they believe in the social relevance of their work and the peculiarities of public work (Houston, 2009).

According to the above theoretical categories and previous empirical results regarding public employees' preferences towards intrinsic HRM practices rather than extrinsic work incentives, we can formulate our first research hypothesis: HRM practices promoting intrinsic work incentives are more positively associated to PSM than HRM practices implementing extrinsic work incentives (H1).

\section{$2.3 \quad P-O f i t$}

Currently, the P-O fit theory is widely used in motivational research in the public sector and is complementary to the PSM approach [for an extensive review of the relations between PSM and P-O fit, see Kim (2012)]. Value congruency (i.e., a high level of P-O fit) is frequently conceptualised as an intermediate variable that comes into play in the relationship between PSM and attitudinal outcomes such as preference for public work (Christensen and Wright, 2011; Steijn, 2008); performance (Bright, 2007); job satisfaction (Wright and Pandey, 2011); or organisational commitment (Kim, 2012). The 
general theorisation of values-congruency in work settings allows for a more precise analysis of the causal link between HRM practices and preferences, and PSM.

$\mathrm{P}-\mathrm{O}$ fit theory relies on the assumption that the individuals in an organisation compare their personal aspirations to their organisational environment in search of congruence. The idea that individuals expect to fulfil some of their personal needs through their membership in a professional organisation is a well-accepted postulate. Diverse needs, motives and values theories focus on the individual (internal) or situational (external) determinants of behaviour (Alderfer, 1969; Herzberg et al., 1959; Maslow, 1954). They all share the claim that motivation arises when individuals seek optimal satisfaction of certain needs. In the wake of this strong claim, it is likely that personal expectations might encounter favourable or unfavourable organisational realities and may thus engender satisfaction or dissatisfaction depending on whether or not those expectations are fulfilled.

$\mathrm{P}-\mathrm{O}$ fit is one of the most popular areas of research in this context. According to this perspective, employees are more willing to be committed, to be satisfied, and to remain in place if they feel that there is a good fit between their preferences, whether intrinsic or extrinsic, and their organisational environment. Numerous studies have demonstrated the positive effect of a high P-O fit on work outcomes, for instance, on job satisfaction or on turnover intentions (Kristof-Brown et al., 2005; Bretz and Judge, 1994).

HRM practices fall under the category of organisational resources and play a fundamental role in the development of an organisational culture. They might thus greatly impact the employees' perception of congruence between their personal expectations and their work environment. In their seminal study, Moynihan and Pandey (2007b, p.41) reveal that organisational (HRM) practices, which are defined as "work-related rules and norms, shape not only the administrative behaviour of public servants but also the basic attitudes that these actors hold about the value of public service". The authors argue that organisational (HRM) practices contribute to producing rules-in-use, which in turn influence employees' behaviours towards their job as well as their organisation.

Employees at organisations with HRM practices that allow them to achieve job autonomy and enable them to fulfil their personal expectations will be more likely to report higher job satisfaction and higher organisational commitment. Such positive individual attitudes can help sustain a high PSM level. Thus, the perceived fit between personal aspirations and work environment might mediate the direct relationship between HRM practices and PSM. In contrast, public employees who feel a sense of non-congruence between organisational practices and their expectations demonstrate more negative attitudes towards their work and organisation, which might in turn contribute to decreasing PSM.

In a nutshell, we believe that the relationships between HRM practices and PSM must be considered through the lens of the fit between individual and organisational values, norms and rules-in-use. The P-O fit approach enables us to empirically investigate how the degree of congruence between individuals' expectations and organisational realities might explain PSM. Furthermore, linking P-O fit to the dichotomy between intrinsic versus extrinsic work incentives (promoted by the respective HRM practices, as discussed above) lead to the formulation of a second research hypothesis: $P$-O fit more positively mediates the relation between HRM practices promoting intrinsic work incentives and PSM level than the relation between HRM practices implementing extrinsic work incentives and PSM (H2). 


\section{Data and method}

The two research hypotheses will be assessed on their merits in the remainder of this article. We present the survey and dataset, and the operationalisation of the main concepts, and then explain the statistical method (i.e., correlations, regression models and mediation analysis) applied for this empirical test.

\subsection{Survey procedure and data sample}

This study uses quantitative survey data from municipal and cantonal civil servants in Switzerland. With the exception of the Italian- and Romansh-speaking municipalities and cantons, which together represent about $7 \%$ of the country's population, all decentralised political entities in Switzerland received an invitation to participate in a survey. Finally, 279 municipalities and nine cantons decided to take part in the empirical study. Depending on their preferences, cantonal and municipal managers could choose between an online or paper-based survey. They were responsible for the distribution of the questionnaire to their subordinates. However, to ensure complete privacy, answers were directly saved in a server belonging to our university. Neither the employees, human resources department, direct supervisors, nor the elected officials had access to this data. The employees were completely and transparently informed regarding this survey procedure.

The survey was eventually given to 10,150 cantonal civil servants who returned 3,131 questionnaires (response rate of $31 \%$ ) and to 9,852 municipal civil servants from whom 3,754 questionnaires were returned (response rate of $38 \%$ ). Table 1 provides the socio-demographic description of the data sample.

Table 1 Description of the sample

\begin{tabular}{lcc}
\hline \multicolumn{3}{c}{ Sample $N=6,885$} \\
\hline Educational level & Wage level & Hierarchical level \\
\hline Secondary school: $2.7 \%$ & Less than $52,000: 17 \%$ & Apprentice, trainee: $3.6 \%$ \\
Professional apprenticeship: $42.3 \%$ & $52,001-78,000: 26.7 \%$ & Auxiliary: $0.6 \%$ \\
High school diploma: $6.9 \%$ & $78,001-104,000: 28.5 \%$ & Employee: $51.9 \%$ \\
Upper professional apprenticeship: $21.9 \%$ & $104,001-130,000: 17.4 \%$ & Manager: $30.4 \%$ \\
University degree: $26.2 \%$ & $130,001-156,000: 7.3 \%$ & Senior manager: $13.5 \%$ \\
Sex & More than $156,000: 3.1 \%$ & \\
Males: $55.9 \%$ & & \\
Females: $44.1 \%$ & & \\
Average age, in years: 43.5 & & \\
\hline
\end{tabular}

\subsection{Measures}

This section briefly introduces how the main variables (i.e., PSM, HRM practices and $\mathrm{P}-\mathrm{O}$ fit) of the study have been operationalised. The details regarding the items used in the questionnaire are exhibited in Appendix. Note also that all scales used to assess a variable achieved acceptable Cronbach's alphas (Nunnally, 1978). 
To measure PSM, a set of eleven items inspired by Perry (1996) was used. The four dimensions of the PSM construct were taken into account, but the items relating to the 'attraction to policy making' dimension were adapted. Only two out of the four original items regarding this specific PSM dimension were kept, as the two retrenched items did not make sense in the Swiss political and administrative context (Giauque et al., 2011). Finally, to reflect the latest advances in PSM measurement, a summative index of the mean of each of the four dimensions was computed.

HRM practices were measured using 11 items inspired from Daley and Vasu (2005) and Spector (1985). In order to better test our two hypotheses, we created two separate variables. The first contained items related to HRM practices promoting intrinsic work incentives, while the second is based on items related to HRM practices promoting extrinsic work incentives. The respondents were asked to indicate how important each of the different HRM practices deployed in their organisation was.

The literature on $P$-O fit offers a great diversity of measurement tools (Kristof, 1996). To capture the congruency between organisational and individual values, we made use of three items directly inspired by attested items (Cable and DeRue, 2002; Kristof-Brown et al., 2005).

As with other studies on PSM antecedents, a number of individual variables were controlled for. These control variables encompassed gender, age, hierarchical level, educational level, and income. As for the other variables presented above, the reader will find the items used and their respective coding in Appendix.

\subsection{Statistical methods}

Three consecutive analytical steps are considered to provide answers to the research hypotheses. The first step is rather descriptive; it assesses how all variables are correlated. The second combines several regression models in order to analyse to what extent (intrinsic and extrinsic) HRM practices are direct predictors of PSM and of P-O fit (i.e., Hypothesis 1) when controlling for the usual socio-demographic variables (gender, age, educational level, hierarchical level, and income). The third step of analysis considers the mediating effect of $\mathrm{P}-\mathrm{O}$ fit on the relation between HRM practices and PSM (i.e., Hypothesis 2) with two lines of inquiry (first identification of mediation effect, then definition of its scope and significance). Mediation analyses are used: "to explain how or why relations between independent and dependent variables exist in reality" [Vandenabeele, (2009), p.19]. To identify if P-O fit mediates the relation between (intrinsic and extrinsic) HRM practices and PSM, a model of regression includes the mediating variable to the model explaining PSM. To do so, the three stages of analysis to assess mediation effect, outlined by Baron and Kenny (1986), and empirically developed in recent academic research (Haar and Roche, 2010; Vandenabeele, 2009), have been systematically followed. Mediation effects are assessed by considering the extent to which beta weights characterising the effect of the independent variables (intrinsic and extrinsic HRM practices) on the dependent one (PSM) is altered when a mediating variable (P-O fit) is entered in the equation. If they are non-significant, then one may conclude full mediation, and if beta weights decrease, then one may conclude partial mediation (Liden et al., 2000). Finally, the Sobel test must be used to confirm whether the difference in beta weights is significant or not: "If this score (score of the Sobel test) exceeds 1.96, this demonstrates statistical significance at a level of .05 or lower" [Vandenabeele, (2009), p.20]. As explained above, methodology used in this study relies 
on regression analyses. According to the fact that this study is an exploratory analysis, regression analyses are an acceptable statistical strategy even if structural equation modelling (SEM) would be more accurate to check internal and external validity with respect to a confirmatory statistical strategy. Therefore, the exploratory dimension of this present study must be underlined and might be considered as a limitation. Further studies must be undergone in order to confirm the results of this empirical research, which will be presented now.

\section{Empirical results}

To test the two research hypotheses, we successively present correlation coefficients, linear regression models and the results of mediation tests.

\subsection{Correlation analyses}

As Table 2 clearly shows, HRM practices, whether intrinsic or extrinsic, are correlated to PSM and, to a larger extent, to P-O fit as well. However, the pattern of relations is quite different considering PSM (i.e., significantly positive for intrinsic HRM practices versus negative and non-significant for extrinsic HRM practices) or P-O fit (significantly positive for both categories of HRM practices, but stronger for intrinsic HRM practices). These first results indicate initial empirical evidence that the types of HRM practices must be taken into account when explaining not only PSM, but P-O fit as well. Additionally, the correlation between P-O fit and PSM is statistically significant and positive. This particular finding also supports the idea of considering the influence of P-O fit (as a mediating variable) on PSM.

Moreover, the respondents who report higher levels of PSM are predominantly men and older employees who possess a high educational level and belong to the higher income categories. Such results confirm previous research regarding socio-demographic antecedents of PSM (Bright, 2005; Pandey and Stazyk, 2008; Perry, 1997; Anderfuhren-Biget, 2012). Furthermore, the civil servants who declare high levels of P-O fit have the same basic type of socio-demographic antecedents. This is a further indication of the multiple links between the three main variables of the theoretical framework. However, to disentangle these relationships and to clarify whether direct effects of HRM practices on PSM are similar to those stated in Hypothesis 1, and/or if indirect effects are present as postulated by Hypothesis 2, we now turn to regression analyses.

\subsection{Regression analyses}

Table 3 presents the results of the regression analysis conducted to assess the direct effects of HRM practices on PSM. The standardised beta coefficients confirm the first hypothesis that expects a more positive relation between the valorisation of intrinsic HRM practices and PSM (0.168) than between extrinsic work incentives and PSM $(-0.050)$. These findings are also in line with those of previous studies demonstrating that public employees prefer intrinsic incentives (Bright, 2009; Pandey and Stazyk, 2008). 
Table 2 Correlations and descriptive statistics of the study variables

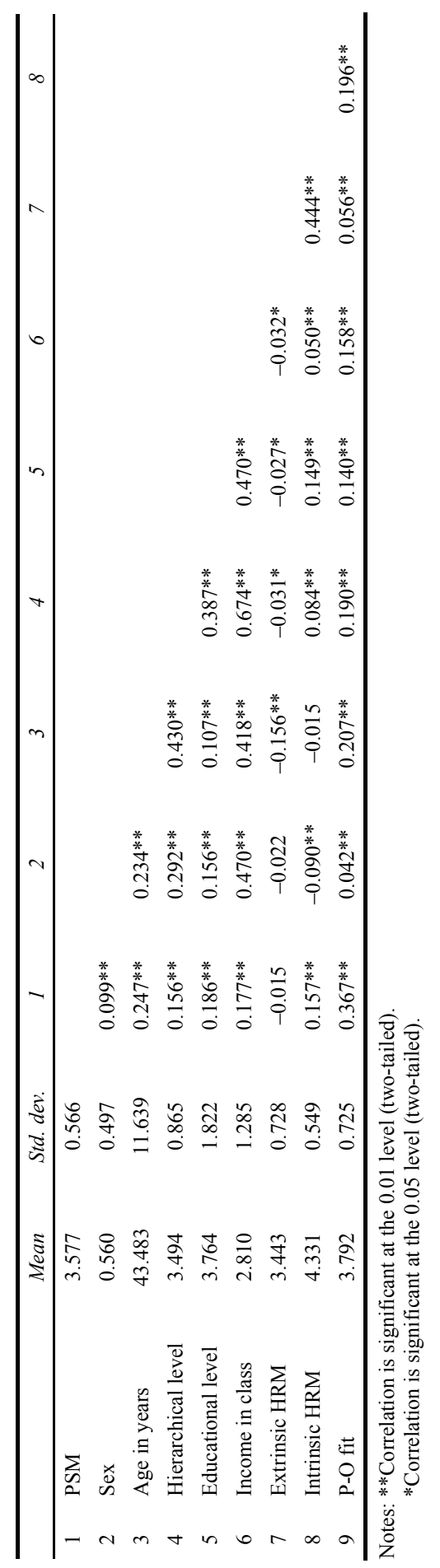


Table 3 Regression analysis for PSM (intrinsic/extrinsic HRM practices)

\begin{tabular}{llcc}
\hline & & Standardised beta $^{\circ}$ & Sig. \\
\hline Control variables & Gender & 0.044 & 0.001 \\
& Age & 0.225 & 0.000 \\
& Hierarchical level & -0.025 & 0.141 \\
& Educational level & 0.136 & 0.000 \\
& Income & 0.005 & 0.784 \\
Adjusted R2 & 0.086 & & 0.000 \\
\hline Predictor variables & Intrinsic HRM & 0.168 & 0.000 \\
& Extrinsic HRM & -0.050 & \\
\hline Total R2 & 0.106 & & \\
R2 change (sig.) & $0.022(0.000)$ & & \\
Total F statistic (sig.) & $107.221(0.000)$ & & \\
\hline
\end{tabular}

Note: ${ }^{\circ}$ displayed coefficients of regression takes into account predictor variables.

In addition (see Table 4), regression analyses also confirm the existence of a significant and positive relationship between HRM practices relying on intrinsic motivators and P-O fit. On the contrary, regression coefficients between extrinsic HRM practices and value congruence are not significant. This is an early indication of the plausibility of our second hypothesis. Moreover, the addition of the two categories of HRM practices to common socio-demographic antecedents contributes unequivocally to the explanation of both PSM (significant R2 change .022) and P-O fit (significant R2 change 0.032). Such a result reinforces the general argument of this study by providing empirical evidence of the need to consider HRM practices in the explanation of PSM level among civil servants. Nevertheless, we have also to stress that our regression models explain a relatively small variance proportion of our dependent variables. This remark suggests that it could be useful to complete the variables' list in order to complete antecedents' factors of PSM and P-O fit.

Table 4 Regression analysis for P-O fit (intrinsic/extrinsic HRM practices)

\begin{tabular}{lccc}
\hline & & Standardised beta $^{\circ}$ & Sig. \\
\hline Control variables & Gender & -0.016 & 0.254 \\
& Age & 0.173 & 0.000 \\
& Hierarchical level & 0.081 & 0.141 \\
& Educational level & 0.068 & 0.000 \\
& Income & -0.002 & 0.936 \\
Adjusted R2 & 0.063 & & \\
\hline Predictor variables & Intrinsic HRM & 0.177 & 0.000 \\
& Extrinsic HRM & 0.009 & 0.535 \\
\hline Total R2 & 0.094 & & \\
R2 change (sig.) & $0.032(0.000)$ & & \\
Total F statistic (sig.) & $107.475(0.000)$ & & \\
\hline
\end{tabular}

Note: ${ }^{\circ}$ displayed coefficients of regression takes into account predictor variables. 
Finally, to identify the potential mediating effect of P-O fit, we should compare the standardised regression coefficients for intrinsic and extrinsic HRM practices without $\mathrm{P}-\mathrm{O}$ fit (see Table 3) to the results of the linear regression with the inclusion of P-O fit as mediating variable (see Table 5). First, the condition for complete mediation (i.e., non-significant coefficients for both types of HRM practices) when the mediating variable is entered) is not met. Such a result is not surprising given the complexity of the social dynamics and the numerous and confounding causes that occur in real life settings (Vandenabeele, 2009). However, this comparison of beta weights indicates that there is some empirical evidence of the partial mediating effect of P-O fit for intrinsic HRM practices (decrease from 0.168 to 0.114 ) but not for extrinsic HRM practices, given the small extent of the variation (0.03).

Table 5 Regression analysis for PSM (intrinsic/extrinsic HRM practices)

\begin{tabular}{llcc}
\hline & & Standardised beta & Sig. \\
\hline Control variables & Gender & 0.049 & 0.000 \\
& Age & 0.173 & 0.000 \\
& Hierarchical level & -0.049 & 0.002 \\
& Educational level & 0.115 & 0.000 \\
& Income & 0.006 & 0.754 \\
Adjusted R2 & 0.086 & & 0.000 \\
\hline Predictor variables & Intrinsic HRM & 0.114 & 0.000 \\
\hline Mediator variable & P-O fit & -0.053 & 0.000 \\
\hline Total R2 & 0.191 & 0.302 & \\
R2 change (sig.) & $0.105(0.000)$ & & \\
Total F statistic (sig.) & $181.450(0.000)$ & & \\
\hline
\end{tabular}

Note: ${ }^{\circ}$ displayed coefficients of regression takes into account predictor and mediator variables.

\subsection{Mediation analyses}

As a third and final step, we proceed to the Sobel's test (Preacher and Leonardelli, 2001) with the aim of confirming whether or not the differences in beta weights for these direct and indirect effects are significant (Preacher and Leonardelli, 2001). The test's results confirmed that P-O fit partially mediates the relationship between intrinsic HRM practices and PSM ( $\mathrm{z}$ score $=10.582$; $\mathrm{p}$-value $=0.000)$. By contrast, mediation is discarded for extrinsic HRM practices $(z$ score $=1.994$; $p$-value $=0.046)$. In other words, value congruency between civil servants and their organisation only intervenes in PSM development for civil servants who valorise intrinsic HRM practices. 
Table 6 Mediation tests

\begin{tabular}{lccccccccc}
\hline \multicolumn{3}{c}{ Sobel test of mediating effect } & & \multicolumn{4}{c}{ Probability } \\
\cline { 1 - 3 } Independent variable & $\begin{array}{c}\text { Mediator } \\
\text { variable }\end{array}$ & $\begin{array}{c}\text { Dependent } \\
\text { variable }\end{array}$ & $\begin{array}{c}\text { Sobel } \\
\text { test }\end{array}$ & & 1-tailed & 2-tailed & $\begin{array}{c}\text { Standard } \\
\text { error }\end{array}$ & p-value \\
\hline Intrinsic satisfaction & P-O fit & PSM & 10.582 & & 0.000 & 0.000 & 0.003 & 0.000 \\
Extrinsic satisfaction & & & 1.994 & & 0.023 & 0.046 & 0.002 & 0.046 \\
\hline
\end{tabular}

In a nutshell, the results from the correlation analyses, regression models and Sobel's test all seem to confirm the two research hypotheses. HRM practices promoting intrinsic work incentives influence the level of PSM reported by civil servants whose values are in line with those of their organisation.

\subsection{Limitations}

The exposition of our main empirical findings remains preliminary, as this study has some limitations related to its cross-sectional research design. First of all, it is worth noting that the method of data collection might be slightly problematic. The answers to the survey were collected at a single point in time. This may raise common method variance concerns and might cause major problems in inferring causality [Haar and Roche, (2010), p.1010]. For instance, we cannot definitively claim that P-O fit is a mediating variable between HRM practices and PSM. A high level of value congruency can be achieved in two principal ways (supplementary and complementary):

\footnotetext{
"From a supplementary standpoint, congruence is achieved when organisations attract individuals who have similar goals and values, whereas from a complementary standpoint, congruence is achieved when the salient unmet needs of individuals are satisfied by the resources and tasks that are provided by organisations". [Bright, (2008), p.152]
}

If we seriously take into account the two mechanisms leading to a high value congruency, then the links between HRM practices, P-O fit and PSM would probably be best conceptualised as multi-directional and, furthermore, as both direct and indirect. In a nutshell, our findings need further confirmation, or revision, from studies using a longitudinal research design that should allow for more robustly testing the direction of causality between our variables. Note however that this kind of methodological challenge is recurrent in studies about HRM practices, PSM, P-O fit and work outcomes [see for instance Kim (2012, pp.836-837)].

A second limitation concerns the relatively small variance proportion of PSM that we are able to explain with our regression models. For instance, HRM practices, whether intrinsic or extrinsic, explain $2.2 \%$ of the variance of PSM in this study (see Table 3 ). In the same vein, HRM practices only explain $3.2 \%$ of the variance of P-O fit (see Table 4 ). According to the latter results, we must concede that this study probably ignores important individual or organisational variables that could explain a more important proportion of our dependent variables' variance. Therefore, further research must be undertaken in order to complete the variables' list, which reveals important relationships with PSM and P-O fit. Nevertheless, if we take into account simultaneously intrinsic and extrinsic HRM practices and P-O fit, our regression model (see Table 5) explains 10.5\% of the PSM variance. This result is therefore not negligible. 


\section{Conclusions}

This article has argued that HRM practices have an influence on the PSM level reported by civil servants whose individual values are consistent with those of their organisation. It provides support for future research investigating the socialisation process within public administrations, i.e., through HRM rules-in-use, which might contribute to developing and sustaining PSM. In this socialisation process, HRM practices promoting intrinsic work incentives and P-O fit do matter. Thus, the type of HRM tools and the congruency between organisation and individual values need to be systematically integrated in theoretical models explaining why civil servants report different levels of PSM. Furthermore, HRM practices and tools greatly contribute to shaping perception of fit between an organisation's characteristics and values, and employees' work values and expectations. In other words, PSM level among public servants might greatly vary according to the HRM practices of a given organisation. This specific result is in line with recent research demonstrating that high commitment human resource practices in public organisations positively affect civic mindedness (Gould-Williams et al., 2013). For instance, in this study, we found that intrinsic HRM practices are positively and significantly related to PSM, whereas extrinsic ones are negatively and significantly related to PSM. This result might suggest that some specific HRM bundles are more prone to favourably impact PSM.

Secondly, it appears to be even more important to look conjointly at HRM practices and value congruency as organisational antecedents of PSM, because both P-O fit and PSM are complementary explanations of work attitudes such as organisational commitment and job satisfaction (Kim, 2012). In other words, identifying the organisational antecedents of PSM is also relevant for scholars interested in work outcomes and performance, as HRM practices might have a direct impact on some work outcomes and/or an indirect impact through PSM level. According to these empirical findings, it is worth considering organisational antecedents of PSM and future research must be encouraged in order to better assess organisational variables' impacts on PSM.

Finally, our empirical results should have practical implications for HRM managers in Switzerland and abroad. This study shows that most of the HRM practices introduced at the cantonal and municipal levels since the new public management reform era have not automatically received favour from public service motivated employees. Current organisational reforms in the public sector clearly give priority to extrinsic HRM practices and tools such as, for instance, pay-for-performance, results-oriented appraisal, and development of competition between employees. These kinds of HRM practices, which are well developed in the private sector, are probably not adapted to public organisations or to their employees (Frey et al., 2013). HRM specialists have demonstrated that contemporaneous organisations make use of HR tools and practices more according to ideological arguments than to empirical evidence (Pfeffer, 2007). The empirical evidence of this article suggests, in contrast to current management orthodoxy, that intrinsic HRM practices might be more in line with public employees' professional expectations. As far as this research is concerned, autonomy, participation in the decision-making, work-life balance, diversified work tasks, and flexible working hours might be considered as positive antecedents of PSM and P-O fit. The use of this bundle of HRM practices might therefore contribute to shaping a more positive organisational environment, which, in turn, might contribute to positive work outcomes. 


\section{References}

Alderfer, C. (1969) 'An empirical test of a new theory of human needs', Organizational Behavior and Human Performance, Vol. 4, No. 2, pp.142-175.

Anderfuhren-Biget, S. (2012) 'Profiles of public service motivated civil servants: evidence from a multicultural country', International Journal of Public Administration, Vol. 35, No. 1, pp.5-18.

Anderfuhren-Biget, S., Varone, F. and Giauque, D. (2013) 'Policy environment and public service motivation', Public Administration [online] http://dx.doi.org/10.1111/padm.12026 (accessed 13 October 2014).

Baron, R. and Kenny, D. (1986) 'The moderator-mediator variable distinction in social psychological research: conceptual, strategic, and statistical considerations', Journal of Personality and Social Psychology, Vol. 51, No. 6, pp.1173-1182.

Bretz, R.D. and Judge, T.A. (1994) 'Person-organization fit and the theory of work adjustment: implications for satisfaction, tenure, and career success', Journal of Vocational Behavior, Vol. 44, No. 1, pp.32-54.

Brewer, G.A. and Walker, R.M. (2010) 'Explaining variation in perceptions of red tape: a professionalism-marketization model', Public Administration, Vol. 88, No. 2, pp.418-438.

Bright, L. (2005) 'Public employees with high levels of public service motivation. Who are they, where are they, and what do they want?', Review of Public Personnel Administration, Vol. 25, No. 2, pp.138-154.

Bright, L. (2007) 'Does person-organization fit mediate the relationship between public service motivation and the job performance of public employees?', Review of Public Personnel Administration, Vol. 27, No. 4, pp.361-379, doi:10.1177/0734371X07307149.

Bright, L. (2008) 'Does public service motivation really make a difference on the job satisfaction and turnover intentions of public employees?', The American Review of Public Administration, Vol. 38, No. 2, pp.149-166.

Bright, L. (2009) 'Why do public employees desire intrinsic nonmonetary opportunities?', Public Personnel Management, Vol. 38, No. 3, pp.15-37.

Cable, D.M. and DeRue, D.S. (2002) 'The convergent and discriminant validity of subjective fit perceptions', Journal of Applied Psychology, Vol. 87, No. 5, pp.875-884.

Camilleri, E. (2007) 'Antecedents affecting public service motivation', Personnel Review, Vol. 36, No. 3, pp.356-377.

Christensen, R.K. and Wright, B.E. (2011) 'The effects of public service motivation on job choice decisions: disentangling the contributions of person-organization fit and person-job fit', Journal of Public Administration Research and Theory, Vol. 21, No. 4, pp.723-743, doi:10.1093/jopart/muq085.

Coursey, D.H. and Pandey, S.K. (2007) 'Content domain, measurement, and validity of the red tape concept: a second-order confirmatory factor analysis', The American Review of Public Administration, Vol. 37 No. 3, pp.342-361.

Daley, D.M. and Vasu, M.L. (2005) 'Supervisory perceptions of the impact of public sector personnel practices on the achievement of multiple goals. Putting the strategic into human resource management', American Review of Public Administration, Vol. 35, No. 2, pp.157-167.

Deci, E.L. and Ryan, R.M. (1985) Intrinsic Motivation and Self-Determination in Human Behavior, Plenum Press, New York.

Frey, B.S., Homberg, F. and Osterloh, M. (2013) 'Organizational control systems and pay-forperformance in the public service', Organization Studies [online] http://oss.sagepub.com/content/early/2013/05/23/0170840613483655.abstract, http://oss.sagepub.com/content/early/2013/05/23/0170840613483655.full.pdf (accessed 13 October 2014). 
Giauque, D., Anderfuhren-Biget, S. and Varone, F. (2013a) 'HRM practices, intrinsic motivators, and organizational performance in the public sector', Public Personnel Management, Vol. 42, No. 2, pp.123-150.

Giauque, D., Resenterra, F. and Siggen, M. (2013b) 'Antecedents of job satisfaction, organizational commitment and stress in a public hospital: a P-E fit perspective', Public Organization Review, Vol. 14, No. 2, pp.201-228.

Giauque, D., Ritz, A., Varone, F., Anderfuhren-Biget, S. and Waldner, C. (2011) 'Putting public service motivation into context: a balance between universalism and particularism', International Review of Administrative Sciences, Vol. 77, No. 2, pp.227-253.

Gould-Williams, J. (2003) 'The importance of HR practices and workplace trust in achieving superior performance: a study of public-sector organizations', International Journal of Human Resource Management, Vol. 14, No. 1, pp.28-54.

Gould-Williams, J. (2007) 'HR practices, organizational climate and employee outcomes: evaluating social exchange relationships in local government', International Journal of Human Resource Management, Vol. 18, No. 9, pp.1627-1647.

Gould-Williams, J.S., Bottomley, P., Redman, T.O.M., Snape, E.D., Bishop, D.J., Limpanitgul, T., et al. (2013) 'Civic duty and employee outcomes: do high commitment human resource practices and work overload matter?', Public Administration [online] http://dx.doi.org/10.1111/padm.12019 (accessed 13 October 2014).

Haar, J.M. and Roche, M.A. (2010) 'Family supportive organization perceptions and employee outcomes: the mediating effects of life satisfaction', The International Journal of Human Resource Management, Vol. 21, No. 7, pp.999-1014.

Herzberg, F., Mausner, B. and Bloch-Snyderman, B. (1959) The Motivation to Work, John Wiley, New York.

Houston, D.J. (2009) 'The importance of intrinsic and extrinsic motivators: examining attitudes of government workers in North America and Western Europe', Paper presented at the International Public Service Motivation Conference, 7-9 June, University of Indiana, Bloomington.

Kim, S. (2009) 'Revising Perry's measurement scale of public service motivation', The American Review of Public Administration, Vol. 39, No. 2, pp.149-163.

Kim, S. (2012) 'Does person-organization fit matter in the public-sector? Testing the mediating effect of person-organization fit in the relationship between public service motivation and work attitudes', Public Administration Review, Vol. 72, No. 6, pp.830-840, doi:10.1111/j.1540-6210.2012.02572.x.

Kim, S., Vandenabeele, W., Wright, B.E., Andersen, L.B., Cerase, F.P., Christensen, R.K., et al. (2013) 'Investigating the structure and meaning of public service motivation across populations: developing an international instrument and addressing issues of measurement invariance', Journal of Public Administration Research and Theory, Vol. 23, No. 1, pp.79-102, doi:10.1093/jopart/mus027.

Kristof, A.L. (1996) 'Person-organization fit: an integrative review of its conceptualizations, measurement, and implications', Personnel Psychology, Vol. 49, No. 1, pp.1-49.

Kristof-Brown, A.L., Zimmerman, R.D. and Johnson, E.C. (2005) 'Consequences of individuals' fit at work: a meta-analysis of person-job, person-organization, person-group, and personsupervisor fit', Personnel Psychology, Vol. 58, No. 2, pp.281-320.

Langbein, L. (2010) 'Economics, public service motivation, and pay for performance: complements or substitutes?', International Public Management Journal, Vol. 13, No. 1, pp.9-23.

Liden, R.C., Wayne, S.J. and Sparrowe, R.T. (2000) 'An examination of the mediating role of psychological empowerment on the relations between the job, interpersonal relationships, and work outcomes', Journal of Applied Psychology, Vol. 85, No. 3, pp.407-416.

Maslow, A. (1954) Motivation and Personality, Harper \& Row, New-York.

Moynihan, D.P. (2010) 'A workforce of cynics? the effects of contemporary reforms on public service motivation', International Public Management Journal, Vol. 13, No. 1, pp.24-34. 
Moynihan, D.P. and Pandey, S.K. (2007a) 'Finding workable levers over work motivation: comparing job satisfaction, job involvement, and organizational commitment', Administration \& Society, Vol. 39, No. 7, pp.803-832.

Moynihan, D.P. and Pandey, S.K. (2007b) 'The role of organizations in fostering public service motivation', Public Administration Review, Vol. 67, No. 1, pp.40-53.

Nunnally, J.C. (1978) Psychometric Theory, McGraw-Hill, New York.

Paarlberg, L.E., Perry, J.L. and Hondeghem, A. (2008) 'From theory to practice: strategies for applying public service motivation', in Perry, J.L. and Hondeghem, A. (Eds.): Motivation in Public Management. The Call of Public Service, pp.268-293, Oxford University Press, Oxford.

Pandey, S.K. and Stazyk, E.C. (2008) 'Antecedents and correlates of public service motivation', in Perry, J.L. and Hondeghem, A. (Eds.): Motivation in Public Management. The Call of Public Service, pp.101-117, Oxford University Press, Oxford.

Perry, J.L. (1996) 'Measuring public service motivation: an assessment of construct reliability and validity', Journal of Public Administration Research and Theory, Vol. 6, No. 1, pp.5-22.

Perry, J.L. (1997) 'Antecedents of public service motivation', Journal of Public Administration Research and Theory, Vol. 7, No. 2, pp.181-197.

Perry, J.L. (2000) 'Bringing society in: toward a theory of public-service motivation', Journal of Public Administration Research and Theory, Vol. 10, No. 2, pp.471-488.

Perry, J.L. and Wise, L.R. (1990) 'The motivational bases of public service', Public Administration Review, Vol. 50, No. 3, pp.367-373, doi: 10.2307/976618.

Pfeffer, J. (2007) 'Human resources from an organizational behavior perspective: some paradoxes explained', Journal of Economic Perspectives, Vol. 21, No. 4, pp.115-134.

Preacher, K.J. and Leonardelli, G.J. (2001) Calculation for the Sobel Test: An Interactive Calculation Tool for Mediation Tests [online] http://quantpsy.org/sobel/sobel.htm (accessed 13 October 2014).

Rainey, H. and Bozeman, B. (2000) 'Comparing public and private organizations: empirical research and the power of the a priori', Journal of Public Administration Research and Theory, Vol. 10, No. 2, pp.447-469.

Ryan, R.M. and Deci, E.L. (2002) Handbook of Self-Determination Research, University of Rochester Press, Rochester, NY.

Scott, P.G. and Pandey, S.K. (2005) 'Red tape and public service motivation', Review of Public Personnel Administration, Vol. 25, No. 2, pp.155-180.

Spector, P.E. (1985) 'Measurement of human service staff satisfaction: development of the job satisfaction survey', American Journal of Community Psychology, Vol. 13, No. 6, pp.693-713.

Steijn, B. (2008) 'Person-environment fit and public service motivation', International Public Management Journal, Vol. 11, No. 1, pp.13-27, doi:10.1080/10967490801887863.

Vandenabeele, W. (2007) 'Towards a public administration theory of public service motivation: an institutional approach', Public Management Review, Vol. 9, No. 4, pp.545-556.

Vandenabeele, W. (2009) 'The mediating effect of job satisfaction and organizational commitment on self-reported performance: more robust evidence of the PSM-performance relationship', International Review of Administrative Sciences, Vol. 75, No. 1, pp.11-34.

Vroom, V.H. (1964) Work and Motivation, Wiley, New-York.

Weibel, A., Rost, K. and Osterloh, M. (2010) 'Pay for performance in the public sector: benefits and (hidden) costs', Journal of Public Administration Research and Theory, Vol. 20, No. 2, pp.387-412, doi:10.1093/jopart/mup009.

Wright, B.E. and Pandey, S.K. (2011) 'Public organizations and mission valence', Administration \& Society, Vol. 43, No. 1, pp.22-44, doi:10.1177/0095399710386303. 


\section{Notes}

1 This paper is part of a broader scientific research project funded by the Swiss National Science Foundation (project fund no. 100012-116086).

\section{Appendix}

Variables and items used in the questionnaire

\begin{tabular}{|c|c|c|}
\hline Variables & Cronbach's alpha & Items \\
\hline \multicolumn{3}{|c|}{$\begin{array}{l}\text { PSM dimension were assessed in relation to the extent to which respondents agreed with the } \\
\text { propositions stated in the items }\end{array}$} \\
\hline \multirow{2}{*}{$\begin{array}{l}\text { Attraction to } \\
\text { policy-making* }\end{array}$} & \multirow[t]{2}{*}{0.917} & I'm very interested in politics \\
\hline & & I like to discuss political subjects with others \\
\hline \multirow{4}{*}{$\begin{array}{l}\text { Commitment } \\
\text { to the public } \\
\text { interest* }\end{array}$} & \multirow[t]{4}{*}{0.636} & $\begin{array}{l}\text { It is important for me to contribute to the common } \\
\text { good }\end{array}$ \\
\hline & & I consider public service my civic duty \\
\hline & & Meaningful public service is very important to me \\
\hline & & $\begin{array}{l}\text { I would prefer seeing public officials do what is best } \\
\text { for the whole community, even if it harms my interest }\end{array}$ \\
\hline \multirow[t]{3}{*}{ Compassion* } & \multirow[t]{3}{*}{0.667} & I'm highly moved by the plight of underprivileged \\
\hline & & Most social programmes are too vital to do without \\
\hline & & $\begin{array}{l}\text { I'm often reminded by daily events tow dependent we } \\
\text { are on one another }\end{array}$ \\
\hline \multirow[t]{2}{*}{ Self-sacrifice* } & \multirow[t]{2}{*}{0.552} & $\begin{array}{l}\text { I'm one of those rare people who would risk a } \\
\text { personal loss to help someone else }\end{array}$ \\
\hline & & $\begin{array}{l}\text { I think people should give back to society more than } \\
\text { they get from it }\end{array}$ \\
\hline \multicolumn{3}{|c|}{$\begin{array}{l}\text { HRM practices were assessed in relation to their importance for the respondent, according to the } \\
\text { following scheme: "It is important for me to have... }\end{array}$} \\
\hline \multirow{6}{*}{$\begin{array}{l}\text { Intrinsic HRM } \\
\text { practices* }\end{array}$} & \multirow[t]{6}{*}{0.722} & ... diversified work tasks \\
\hline & & ... independency at work \\
\hline & & ... flexible working hours \\
\hline & & ... the possibility to influence important decisions \\
\hline & & $\begin{array}{l}\text {... the possibility to conciliate private and professional } \\
\text { life }\end{array}$ \\
\hline & & ... good relationship with my colleagues \\
\hline \multirow{5}{*}{$\begin{array}{l}\text { Extrinsic HRM } \\
\text { practices* }\end{array}$} & \multirow[t]{5}{*}{0.700} & ... high work security \\
\hline & & ... high wage \\
\hline & & ... high pay for performance \\
\hline & & ... good career perspectives \\
\hline & & ... a prestigious job \\
\hline
\end{tabular}

Note: *All items are measured on a five points agreement scale: $1=$ 'do not agree at all' to $5=$ 'totally agree'. 
Variables and items used in the questionnaire (continued)

\begin{tabular}{|c|c|c|}
\hline Variables & Cronbach's alpha & Items \\
\hline \multicolumn{3}{|c|}{$\begin{array}{l}P-O \text { fit was assessed in relation to the extent to which respondents agreed with the propositions } \\
\text { stated in the items }\end{array}$} \\
\hline \multirow[t]{3}{*}{ P-O fit* } & 0.716 & $\begin{array}{l}\text { My values, goals and personality fits well with those of } \\
\text { my organisation and its collaborators }\end{array}$ \\
\hline & & What my organisation stands for is important to me \\
\hline & & $\begin{array}{l}\text { If my organisation's values were other, I would find it } \\
\text { less attractive (reversed) }\end{array}$ \\
\hline $\begin{array}{l}\text { Control } \\
\text { variables }\end{array}$ & Coding & Wording \\
\hline Age in years & & Please indicate your birth year \\
\hline Gender & Female $=0$, male $=1$ & What is your gender? \\
\hline $\begin{array}{l}\text { Level of } \\
\text { education }\end{array}$ & $\begin{array}{c}\text { Scale from } 1 \\
\text { (secondary school) to } \\
5 \text { (university degree) }\end{array}$ & What is the highest level of study you have attained? \\
\hline Income & $\begin{array}{l}\text { Scale form } 1 \text { (less } \\
\text { than } 52,000) \text { to } 5 \\
\text { (more than } 156,000)\end{array}$ & What is your gross annual income? \\
\hline $\begin{array}{l}\text { Hierarchical } \\
\text { level }\end{array}$ & $\begin{array}{c}\text { Scale from } 1 \\
\text { (apprenticeship) to } 5 \\
\text { (top-level manager or } \\
\text { specialist) }\end{array}$ & What is your hierarchical position? \\
\hline
\end{tabular}

Note: *All items are measured on a five points agreement scale: $1=$ 'do not agree at all' to $5=$ 'totally agree'. 